\title{
Collaborative Learning- and Quiz-based Teaching Strategy in Biochemistry and Molecular Biology
}

\author{
Yanli Yang, Jie Zhong, Enzhong Li* \\ School of Biological and Food Processing Engineering, Huanghuai University, 76 Kaiyuan Road, Zhumadian 463000, CHINA.
}

\begin{abstract}
Aim: An experimental teaching and learning program used in biochemistry and molecular biology with first-year students in the second term in the Faculty of Biological Sciences at Huanghuai University, China. Materials: Sixty students were divided randomly into two sections ( $n=30$ per section). Students in one section were divided randomly into five groups (six students in each group) and taught using a hybrid collaborative learning and lecture method (experimental section). The second section was taught using a traditional teaching method (control section). To assess achievement, examinations were carried out at the end of every textbook chapter and a final examination in biochemistry and molecular biology was administered at the end of the course. To determine students' attitude to the teaching methods used, a questionnaire survey was conducted at the end of the term. Results: Results showed that students preferred the experimental method. In the experimental section, students' scores were significantly higher than those of students in the control section both in the chapter and the final examinations $(p<0.05)$. Results indicate that the collaborative learning- and quiz-based teaching and learning style is superior to the traditional method of teaching and learning biochemistry and molecular biology.
\end{abstract}

Key words: Biochemistry and molecular biology, Teaching method, Learning method, Collaborative learning-based lecture, Collaborative quiz-based.

\section{INTRODUCTION}

Biochemistry and molecular biology is a basic course in the biological curriculum. Traditionally, the teaching of biochemistry and molecular biology relies heavily on abstract molecule-structure- and biochemistry-reaction-based didactic lectures. In this traditional teacher-centered method of teaching and learning, the teacher delivers information and students passively receive knowledge mainly through theoretical lectures. This teaching strategy might not stimulate students' interest in biochemistry and molecular biology and might even discourage students from studying. With recent changes to the medical curricula, biochemistry and molecular biology is increasingly being taught in several different ways. ${ }^{1-4}$ The value of collaborative learning has received increased attention in recent years. ${ }^{5}$ In our previous article collabo- rative quiz-based teaching strategy in histology, we found that collaborative quiz can be considered as an effective teaching and learning strategy. ${ }^{6}$ In this article, we introduce a new teaching style for a course in biochemistry and molecular biology which incorporates both the merits of collaborative learning-based and collaborative quiz-based teaching and learning style. As a result of the present study, we expect to change the teacher-centered teaching strategy into one that is centered on students.

\section{MATERIALS AND METHODS}

\section{Students and the Collaborative Learning- and Quiz-based Teaching Strategy}

Sixty students at the Faculty of Biological Sciences at the Huanghuai University of
Submission Date: 08-04-2018; Revision Date: 31-10-2018; Accepted Date: 14-11-2018

DOI: 10.5530/ijper.53.2.27 Correspondence: Prof. Enzhong Li, School of Biological and Food Processing Engineering Huanghuai University, 76 Kaiyuan Road, Zhumadian 463000, CHINA.

Phone: 86-396-2853021

E-mail: enzhongli@163.com 
China were divided randomly into two sections, one of which was an experimental section and the other a control section ( $n=30 /$ section). The experimental section was taught using the collaborative learning- and quiz-based teaching and learning strategy and the control section was taught using the traditional teaching and learning method. The procedure used in the experimental section was as follows: First, students were required to preview the course material before each chapter. And the quiz topics were given to students at the beginning of each chapter. Second, Thirty students were divided randomly into five groups ( $n=30 /$ group) and collaborative learning directed by themselves were performed. Students were allowed to discuss the course material to each other in any form. Third, Collaborative quizzes were performed at the end of each chapter and students were allowed to interact and discuss questions about the quiz topics with partners. Fourth, at the end of the quizzes, one student out of each group was randomly required to answer some questions about the course material that was taught. The student's score was regarded as the group's score. Students in the control section were also required to preview the course material before each chapter.

\section{Questionnaire}

A questionnaire was distributed to students in both the experimental and control sections using the previous procedure. $^{6-8}$ The demographic method was used to collect information about the students. The questionnaire, which was distributed to all of the students, was completely anonymous. The distribution of answers was analyzed as percentages of the total number of students in each 30-student section. The contents of the questionnaire are shown in Box 1.

\section{Final examination}

Both sections took the same final examination, which comprised of five different sections. The first section consisted of 40 fill-in-the-blank questions, the second section consisted of 40 multiple-choice questions, the third section consisted of 30 true/false statements, the fourth section consisted of 5 short-essay questions and the fifth section consisted of 5 essay questions. Each student in both experimental section and control section was required to complete all the questions independently.

\section{Statistical analysis}

Data were all expressed as $M \pm S D$. Data analysis was performed using univariate ANOVA and was considered statistically significant at $p<.05$.

\section{RESULTS}

\section{Final examination}

Figure 1 and Table 1 show the mean and standard deviation of the percentage of correct answers in every test section (fill-in-the-blanks questions, single-bestresponse multiple-choice, true/false, short-essay questions and essay questions) on the final examination. Statistical analysis showed that the scores of various types of questions of the students in the experimental section were significantly higher than those of the students in the control section $(p<.05)$. The final average score in the experimental section $(90 \pm 2 \%)$ was significantly higher $(p<.05)$ than that of students in the control section $(76 \pm 1 \%)$.

\section{Questionnaire survey}

All of the students returned the questionnaire and the results are presented in Table 2 and 3.

\begin{tabular}{|c|c|c|c|c|c|}
\hline \multicolumn{6}{|c|}{ Table 2: Student attitude toward the teaching-learning method. } \\
\hline Sections * & $\begin{array}{c}\text { Strongly } \\
\text { disapprove (\%) }\end{array}$ & Disapprove (\%) & $\begin{array}{c}\text { Neither approve } \\
\text { nor disapprove (\%) }\end{array}$ & $\begin{array}{c}\text { Approve } \\
\text { (\%) }\end{array}$ & $\begin{array}{c}\text { Strongly approve } \\
\text { (\%) }\end{array}$ \\
\hline Experimental section & 3.5 & 7 & 26.5 & 35 & 28 \\
\hline Control section & 11 & 29.5 & 25.5 & 20.5 & 13.5 \\
\hline
\end{tabular}

* $\mathrm{n}=30$, respectively

\begin{tabular}{|c|c|c|c|c|c|c|}
\hline Section* & Blanks & Single best & True/false & Short essay & Essay & Average score \\
\hline Experimental section & $81 \pm 4.5$ & $94 \pm 4.1$ & $89 \pm 2.6$ & $83 \pm 3.3^{\#}$ & $79 \pm 3^{\#}$ & $90 \pm 2 \#$ \\
\hline Control section & $77 \pm 5$ & $85 \pm 4.5$ & $85 \pm 2$ & $69 \pm 3.1$ & $63 \pm 3$ & $76 \pm 1$ \\
\hline
\end{tabular}

* $\mathrm{n}=30$, respectively. ${ }^{\#} P<0.05$ vs control section 


\begin{tabular}{|c|c|c|c|c|c|}
\hline \multicolumn{6}{|c|}{ Level of understanding } \\
\hline Sections * & None (\%) & General (\%) & Good (\%) & Very good (\%) & Excellent (\%) \\
\hline Experimental section & 2.5 & 5.0 & 46.0 & 31.0 & 16.0 \\
\hline Control section & 8.0 & 45.0 & 22.0 & 18.5 & 6.5 \\
\hline
\end{tabular}

* $n=30$, respectively

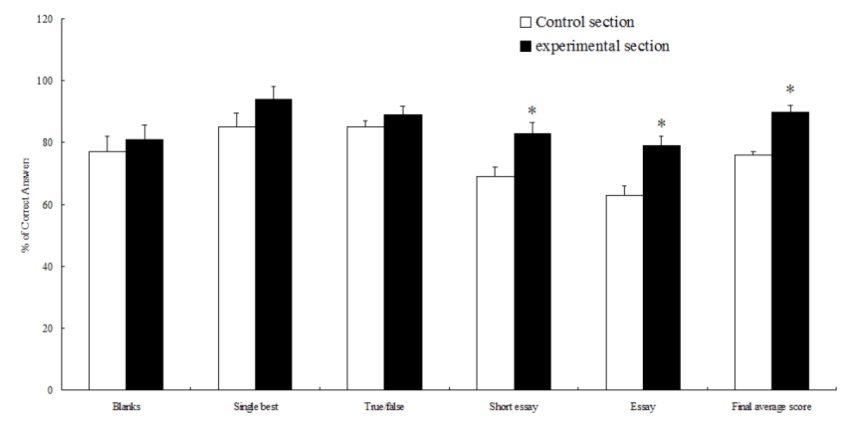

Figure 1: Percentage of students' correct answers on the different sections of the final exam (M $\pm \mathrm{SD})$. ${ }^{*} \boldsymbol{P}<0.05$ vs control section (original).

\section{DISCUSSION}

Collaborative learning, which allowed students to work together towards a shared understanding of concepts or materials taught, is a well-established pedagogy. ${ }^{9}$ Collaborative learning environment are more responsible for their own learning and tend to have a more positive attitude toward the subject matter. ${ }^{10}$ In recent years, collaborative testing was studied by many researchers and the value was confirmed. ${ }^{5,6,8}$ Collaborative testing is helpful not only to low-performing students but also to outstanding students. ${ }^{11}$ Quiz-based and collaborative teaching strategies have previously been found to be efficient in improving laboratory exercises. ${ }^{12}$ In previous studies, collaborative testing was used as a method of assessing students' achievement and teachers' effectiveness. ${ }^{5,13}$ However, quizzes with collaborative learning were used as learning tools in the present study, in which partners learn from each other, help each other and supervise each other. In our collaborative-quiz style, the teacher randomly chooses one student out of each group to answer some questions and this student's score will be regarded as the group's score. Each individual must be responsible for their group, so our collaborative quizzes were more conducive to cultivating a student's sense of responsibility.

To assess the effect of the collaborative learning- and quiz-based teaching and learning strategy, final examination was performed. And the results showed that the scores of students in the experimental section were significantly higher than that of students in the control section. These findings indicated our teaching strategy used in the experimental section in the present study is an effective teaching and learning tool. The traditional teaching and learning style is a teacher-centered program in which students are passively received the knowledge. In fact, the hybrid collaborative learning and collaborative quiz used in experimental section in the present study is a student-centered teaching and learning mode. The students learned mainly through self-directed style and by discussing with subgroup partners.

To assess the student attitude to the teaching and learning method, questionnaire survey was conducted. The results showed that students appreciate the collaborative learning- and collaborative quiz-based teaching strategy better. They think when students learn with others, they have emotional and intellectual support that allows them to go beyond their present knowledge. Collaboration allows them to become more engaged in learning by encouraging discussion and encouraging greater effort. And collaboration makes them understand the teaching-learning material better than they do when learn independently.

It is worth noting that the average scores for short-essay questions and essay questions in experimental section were significantly higher than those in control section. The scores of other examination questions presented no statistically significant difference between the two sections. We speculate the reasons lie in the fact that short-essay questions and essay questions involve profound issues and the students were developed the ability to think deeply through the collaborative learningand collaborative quiz-based teaching and learning style. Students so answered during the questionnaire.

\section{CONCLUSION}

Collaborative earning- and quiz-based teaching and learning style is an effective teaching and learning method in biochemistry and molecular biology.

\section{ACKNOWLEDGEMENT}

We thank the students who participated in the study for their cooperation. This work was supported by the Key Projects of Educational and Teaching Reform of 
Huanghuai University (grant number 2018XJGLX0101); the Major Science and Technology Projects of Zhumadian, Henan, China (grant number 17702).

\section{CONFLICT OF INTEREST}

The authors declare no conflict of interest.

\section{REFERENCES}

1. Kleinsorgen C, Köckritz-Blickwede MV, Naim HY, Branitzki-Heinemann K, Kankofer M, Mándoki M, et al. Impact of Virtual Patients as Optional Learning Material in Veterinary Biochemistry Education. Journal of Veterinary Medical Education. 2017.

2. Ryan MT, Sweeney T. Integrating Molecular Biology into the Veterinary Curriculum. Journal of Veterinary Medical Education. 2007;34(5):658-73.

3. Kat CA, Oliver-Hoyo MT. Creating 3D physical models to probe student understanding of macromolecular structure. Biochemistry and Molecular Biology Education. 2017;45(6):491-500.

4. Cassidy RT, Laura LL. Using molecular visualization to explore protein structure and function and enhance student facility with computational tools. Biochemistry and Molecular Biology Education. 2017;45(4):318-28.

5. Joanne T, Simone EV, John RB. Collaborative, Case-based Learning: How Do Students Actually Learn from Each Other?. Journal of Veterinary Medical Education. 2009;36(3):297-304.
6. Enzhong Li, Yuping G. Collaborative Quiz-Based Teaching Strategy in Histology. Journal of Veterinary Medical Education. 2014;41(3):318-20.

7. Gahutu JB. Physiology teaching and learning experience in a new modular curriculum at the National University of Rwanda. Adv Physiol Educ. 2010;34(1):11-4. http://dx.doi.org/10.1152/ advan. 00093.2009. Medline: 20237228 .

8. Enzhong L, Yanfang C. An Experimental Teaching-Learning Program in Histology. Journal of Veterinary Medical Education. 2011;38(3):334-6.

9. Rutherford S. E pluribus unum: the potential of collaborative learning to enhance Microbiology teaching in higher education. FEMS Microbiol Lett. 2015;362(23):1-6.

10. Mueller-Joseph LJ, Nappo-Dattoma L. Collaborative learning in pre-clinical dental hygiene education. J Dent Hyg. 2013;87(2):64-72.

11. Kapitanoff $\mathrm{SH}$. Collaborative testing: Cognitive and interpersonal processes related to enhanced test performance. Active Learn High Educ. 2009;10(1):56-70. http://dx.doi.org/ 10.1177/1469787408100195.

12. Berg RMG, Plovsing RR, Damgaard M. Teaching baroreflex physiology to medical students: a comparison of quiz-based and conventional teaching strategies in a laboratory exercise. Adv Physiol Educ. 2012;36(2):147-53. http:// dx. doi. org/ 10. 1152/ advan.00011.2012. Medline:22665430.

13. Enzhong Li, Yanfang C. An Experimental Teaching-Learning Program in Histology. Journal of Veterinary Medical Education. 2011;38(3):414-6.

\section{PICTORIAL ABSTRACT}

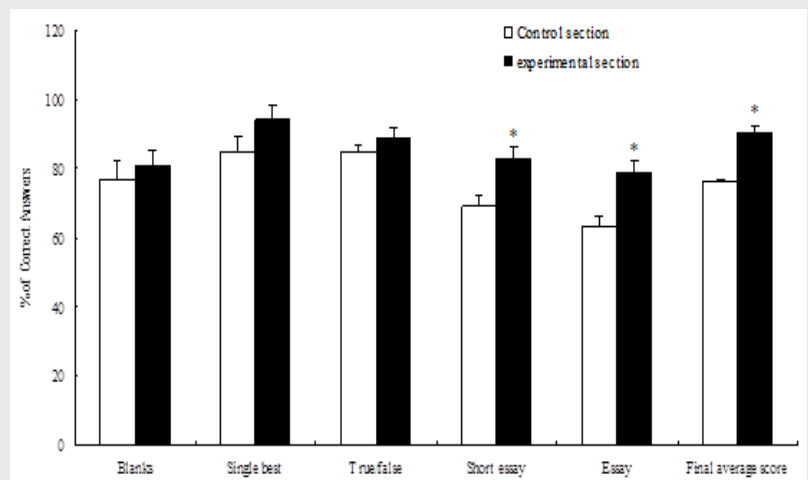

Percentage of students' correct answers on the different sections of the final exam

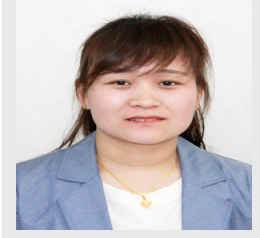

Jie Zhong, is a teacher of Huanghuai University, 76 Kaiyuan Road, Zhumadian 463000, China.

\section{SUMMARY}

- The collaborative learning- and quiz-based teaching and learning style used in the previous study is superior to the traditional method of teaching and learning biochemistry and molecular biology

\section{ABOUT AUTHORS}

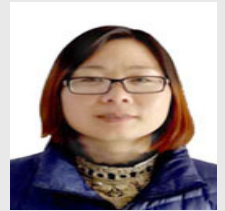

Yanli Yang, is a teacher of Huanghuai University, 76 Kaiyuan Road, Zhumadian 463000, China.

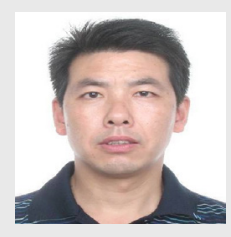

Enzhong Li, $\mathrm{PhD}$, is Professor and Chief of the Animal Reproduction Research Centre of Huanghuai University, 76 Kaiyuan Road, Zhumadian 463000, China. Email: enzhongli@163.com. His research interests include animal reproduction and integrated teachinglearning methods.

Cite this article: Yang Y, Zhong J, Li E. Collaborative Learning- and Quiz-based Teaching Strategy in Biochemistry and Molecular Biology. Indian J of Pharmaceutical Education and Research. 2019;53(2):208-11. 